Article

\title{
Aerodynamic Characteristics of New Volleyball for the 2020 Tokyo Olympics
}

\author{
Sungchan Hong ${ }^{1, * \mathbb{D}}$, Hiroki Ozaki ${ }^{2}$, Keita Watanabe ${ }^{3}$ and Takeshi Asai ${ }^{1}$ \\ 1 Faculty of Health and Sport Sciences, University of Tsukuba, Tsukuba 305-8574, Japan; \\ asai.takeshi.gf@u.tsukuba.ac.jp \\ 2 Japan Institute of Sports Sciences, Tokyo 115-0056, Japan; hiroki.ozaki@jpnsport.go.jp \\ 3 Faculty of Culture and Sport Policy, Toin University of Yokohama, Yokohama 225-8503, Japan; \\ keita.watanabe@toin.ac.jp \\ * Correspondence: hong.sungchan.fu@u.tsukuba.ac.jp; Tel.: +81-29-853-2650
}

Received: 8 April 2020; Accepted: 30 April 2020; Published: 7 May 2020

\begin{abstract}
The pattern of a modern volleyball is greatly different from that of a conventional volleyball, with several changes being made to the shape and design of the surface on the ball. Furthermore, at the 2020 Tokyo Olympics, a new volleyball (V200W; Mikasa) with 18 panels will be shown as the official ball. Therefore, this study compared the basic aerodynamic characteristics of conventional volleyballs with those of new designs in a wind tunnel. We used three full-size FIVB (Fédération Internationale de Volley-Ball) official volleyballs (V5M5000; Molten, MVA200; Mikasa and V200W; Mikasa) to determine the aerodynamic forces acting on each ball. The results indicate that the critical Reynolds number $\left(R e_{c r}\right)$ differed depending on the ball types and their orientations. The $R e_{c r}$ for the Molten ball (conventional) was determined to be $\sim 3.4 \times 10^{5}(C d=0.17)$ on panel orientation A and $\sim 2.7 \times 10^{5}(C d=0.14)$ on panel orientation B. Moreover, the $R e_{c r}$ for the conventional Mikasa ball was determined to be $\sim 2.6 \times 10^{5}(C d=0.14)$ on panel orientation A and $\sim 3.0 \times 10^{5}(C d=0.13)$ on panel orientation B. On the other hand, the critical Reynolds number for the new volleyball (V200W) was $\sim 2.9 \times 10^{5}(\mathrm{Cd}=0.17)$ in the panel orientation A and $\sim 2.6 \times 10^{5}(\mathrm{Cd}=0.15)$ in panel orientation $\mathrm{B}$. From these results, it can be hypothesized that, during a float serve, the flight trajectory will change depending on the type of volleyball and their orientation.
\end{abstract}

Keywords: aerodynamics; Tokyo Olympics; volleyball

\section{Introduction}

The shape and design of volleyballs have substantially changed in recent years. Volleyballs are typically composed of a total of six planes, each of which is formed by three rectangle panels, totaling 18 panels. In 2008, a dimple-style eight-panel design ball (MVA200 by Mikasa), substantially different from conventional official balls, made its debut in the volleyball games at the Beijing Olympics. The use of this ball continued at the 2008 Beijing Olympics and 2016 Rio Olympics, with this ball still being officially used in international competitions such as the FIVB (Fédération Internationale de Volley-Ball) World League. Subsequently, a volleyball with a raised hexagon-shaped design on the surface (V5M5000 by Molten) was introduced in 2008 and has been adopted as the official ball by the NCAA (National Collegiate Athletic Association) Volleyball tournament and the USA Volleyball. The aerodynamic characteristics of these balls, having significantly different shapes and surface textures from those of traditional volleyballs, have been studied previously using wind-tunnel experiments [1-3]. Moreover, wind-tunnel experiments and CFD tests on various sports balls have been performed in previous studies [4-13]. A recent study on the aerodynamic characteristics of soccer balls has indicated that the positional relation of the seams of the ball varies depending on the position of the panels, 
thereby changing the forces acting on the ball [5]. It is considered that the aerodynamic characteristics of volleyballs also change according to the roughness of the ball surface and the positional relation of the seams (e.g., width, depth, and length).

However, as there have not been any studies conducted on the aerodynamic and flight characteristics of the new official volleyball (V200W, 18-panels by Mikasa) to be used in the 2020 Tokyo Olympics, an investigation into these was sought. This study examined primarily the effect of panel orientation on the aerodynamic characteristics, flight characteristics, and aerodynamic force variation of the V200W ball, and compared the results with those of the balls used in the 2018 FIVB World League (MVA200, 8-panels by Mikasa) and the 2018 USA Volleyball (V5M5000, 18-panels by Molten).

\section{Methods}

\section{Wind Tunnel Experiment}

This experiment took place in the closed-circuit wind tunnel (by San Technologies Co., LTD, Tochigi, Japan) at the University of Tsukuba. The maximum flow velocity of this wind tunnel was $55 \mathrm{~m} / \mathrm{s}$, the blower outlet size was $1.5 \mathrm{~m} \times 1.5 \mathrm{~m}$, the flow velocity distribution was within $\pm 0.5 \%$, and the turbulence was $0.1 \%$ or less. Furthermore, in the measuring system of this study, the dynamic pressure can be measured automatically with $0.1 \mathrm{~m} / \mathrm{s}$ intervals by means of the Pitot-static tube placed above the measuring portion of the volleyball. In addition, because the position of the ball during the measurement procedure is set almost at the center of the nozzle cross section to adjust the distance between the nozzle and the ball to zero, the flow generated from the Pitot tube may not have a direct effect on the flow around the ball. Furthermore, the length of the sting used in this study was $0.8 \mathrm{~m}$ and its width was $0.02 \mathrm{~m}$ (Figure 1). The diameter of the volleyball used in this study was uniformly $0.2 \mathrm{~m}$, its weight was $0.269 \pm 0.002 \mathrm{~kg}$, and its internal pressure was set to $0.3 \mathrm{kgf} / \mathrm{cm}^{2}$. The official balls of the 2020 Tokyo Olympics (V200W), 2018 FIVB World League (MVA200), and 2018 USA Volleyball league (V5M5000) were fixed and tested in the wind tunnel as shown in Figure 1. Furthermore, aerodynamic measurements for each volleyball were performed three times and their average values were compared. In this study, aerodynamic measurements for each volleyball were performed for wind speeds (Reynolds number) from $7 \mathrm{~m} / \mathrm{s}$ (approximately $R e=1.0 \times 10^{5}$ ) to $35 \mathrm{~m} / \mathrm{s}$ (approximately $R e=5.5 \times 10^{5}$ ) at intervals of $1 \mathrm{~m} / \mathrm{s}$.

$$
\operatorname{Re}=v D / v
$$

where Reynolds number $(R e)$ is a dimensionless number defined as the ratio of inertial force to viscous force, $v$ is the wind speed $(\mathrm{m} / \mathrm{s}), D$ is the ball diameter $(\mathrm{m})$, and $\mathrm{v}$ is the kinematic viscosity $\left(\mathrm{m}^{2} / \mathrm{s}\right)$, as shown in Equation (1).
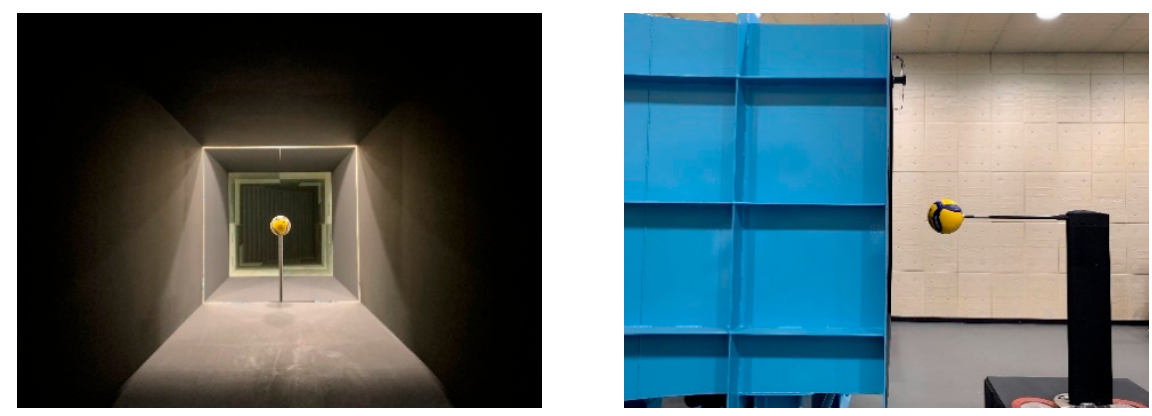

Figure 1. Wind tunnel setup.

In this experiment, the orientation of the panels was divided into two (Face A and B), and the aerodynamic characteristics of the balls in the respective panel orientations were measured (Figure 2). The orientation where the center of the front face is at the center was set as Face A, and the point where all the seams meet at the lower left of the front face was set as Face B. The aerodynamic force on the 
respective balls was measured between wind velocities $(U)$ of $7 \mathrm{~m} / \mathrm{s}$ and $35 \mathrm{~m} / \mathrm{s}$ at $1 \mathrm{~m} / \mathrm{s}$ intervals. Air forces acting on a mounted ball were measured during a $10 \mathrm{~s}$ time interval by a sting-type six-component force detector (model number LMC-61256 by Nissho Electric Works Co, Ltd). Data recording was done on a personal computer with an A/D (Analog to Digital) converter board that has a $1000 \mathrm{~Hz}$ sampling rate. The aerodynamic forces measured in this experiment were converted into a drag coefficient $(C d)$, lift coefficient $(C l)$, and side force coefficient $(C s)$, as shown in Equations (2)-(4), respectively.

$$
\begin{aligned}
& C_{d}=\frac{2 D}{\rho U^{2} A} \\
& C_{l}=\frac{2 L}{\rho U^{2} A} \\
& C_{s}=\frac{2 S}{\rho U^{2} A}
\end{aligned}
$$

where $\rho$ is the air density, expressed as $\rho=1.2 \mathrm{~kg} / \mathrm{m}^{3} ; U$ is the flow rate; and $A$ is the projected area of the volleyball, expressed as $A=\pi \times 0.1^{2}=0.0314 \mathrm{~m}^{2}$.

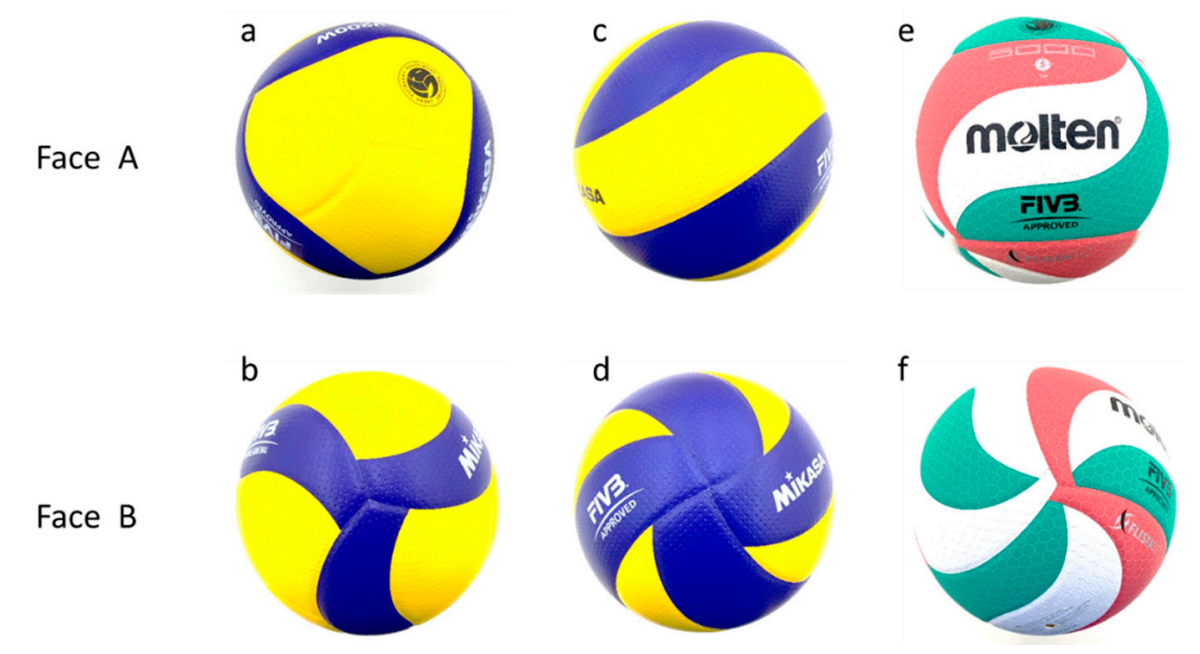

Figure 2. Volleyballs used in the experiment and their panel orientation settings. In this figure, $(\mathbf{a}, \mathbf{b})$ represent the Face A and B orientation of the new Mikasa volleyball (V200W), respectively; (c,d) represent the Face A and B orientations of the old Mikasa volleyball (MVA200), respectively; and $(\mathbf{e}, \mathbf{f})$ represent the Face A and B orientation of the old Molten volleyball (V5M5000), respectively.

\section{Results}

\subsection{Drag Coefficient Variation by Ball}

Figure 3 shows the drag characteristic curves of the respective balls based on their panel orientation. The panel orientation of the respective balls was divided into two faces (Face A and B), and the respective drag coefficients were measured for each face. Most notably, the drag generated for the three types of balls varied substantially according to the ball type. The results showed that drag on the traditional Mikasa (MVA200) and Molten (V5M5000) balls varied significantly depending on the orientation of the ball panels (Figure 3c-f). The new volleyball for the 2020 Tokyo Olympics (V200W), on the other hand, showed relatively small drag variation with changes in panel orientation (Figure 3a,b). 


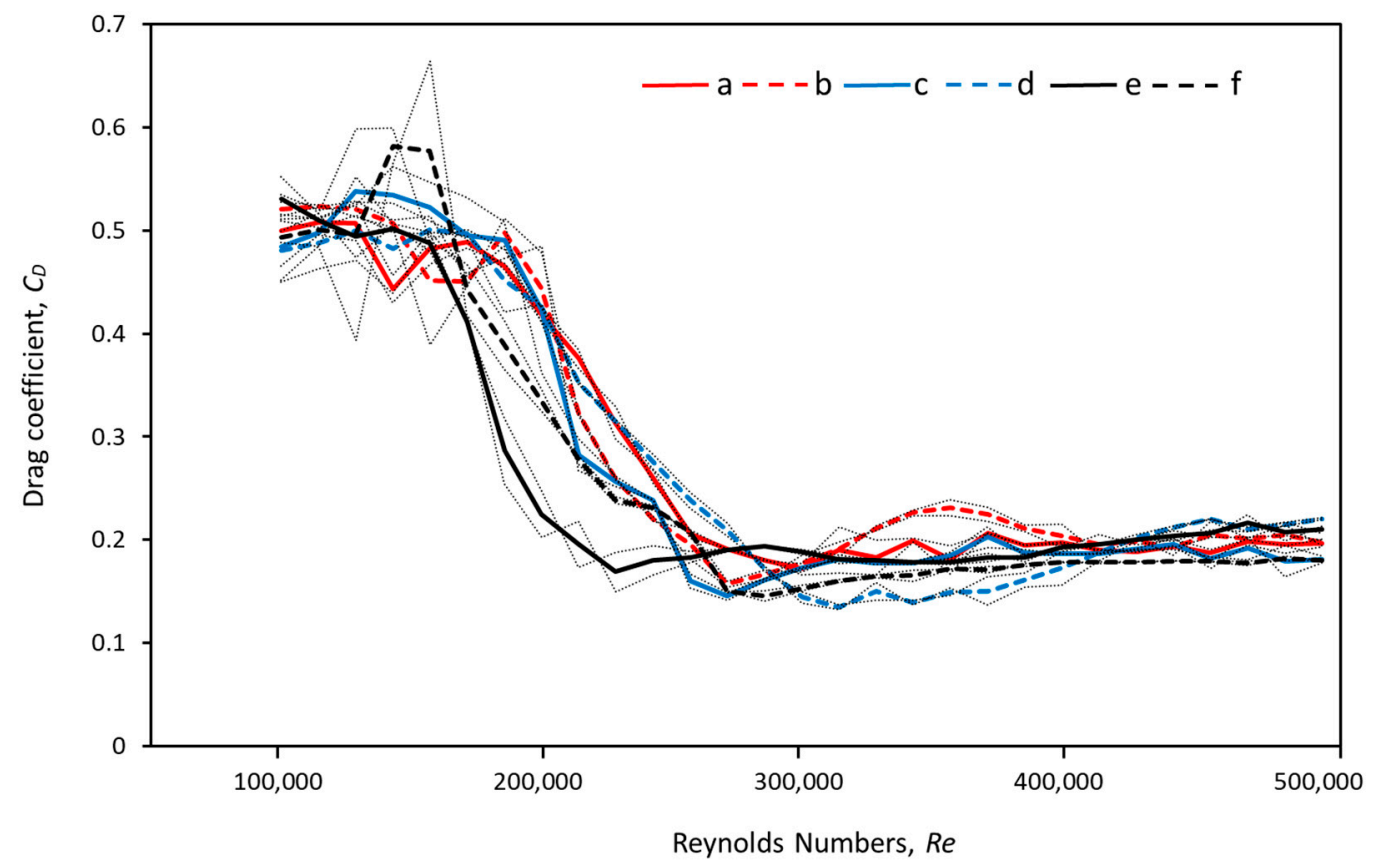

Figure 3. Drag coefficient variation of the balls. In this figure, $(\mathbf{a}, \mathbf{b})$ represent the Face $A$ and $B$ orientation of the new Mikasa volleyball, respectively; (c,d) represent the Face A and B orientations of the old Mikasa volleyball, respectively; and $(\mathbf{e}, \mathbf{f})$ represent the Face A and B orientation of the old Molten volleyball, respectively.

The critical Reynolds number of the respective balls was also found to vary according to the orientation of the panels. The moment at which the flow state of the ball spin changes from laminar to turbulent is called a transition, and the Reynolds number of this transition is called the critical Reynolds number $\left(R e_{c r}\right)$. The $R e_{c r}$ of the new Mikasa volleyball (V200W) was $\sim 2.9 \times 10^{5}(C d \approx 0.17)$ for Face $\mathrm{A}$ and $\sim 2.7 \times 10^{5}(C d \approx 0.15)$ for Face B. The $C d$ value of Face A of the new volleyball was particularly high relative to the other balls. The $R e_{c r}$ of the old Mikasa volleyball (MVA200) was $\sim 2.7 \times 10^{5}(C d \approx 0.14)$ for Face $\mathrm{A}$, and $\sim 3.1 \times 10^{5}(C d \approx 0.13)$ for Face $\mathrm{B}$, indicating that the $C d$ value of Face $\mathrm{B}$ of the old Mikasa ball was low relative to the other balls. The $R e_{c r}$ of the old Molten volleyball $(\mathrm{V} 5 \mathrm{M} 5000 \mathrm{~W})$ was $\sim 2.2 \times 10^{5}(\mathrm{Cd} \approx 0.16)$ for Face A and $\sim 2.8 \times 10^{5}(\mathrm{Cd} \approx 0.14)$ for Face B.

\subsection{Changes in the Lift and Side Forces Over Time}

The next graphs show the irregular force fluctuation in the horizontal and vertical directions of each volleyball when a wind velocity of $15 \mathrm{~m} / \mathrm{s}$ is applied for $10 \mathrm{~s}$ (Figure 4). Therefore, these are the scatter diagrams of the changes in the lift and side forces applied to different types of volleyball and panel orientations for $10 \mathrm{~s}$. From Figure 4, it is possible to verify that the irregular forces (lift and side forces) acting on the ball varied depending on the type of volleyball. These results also showed that if the panel orientation changed for a volleyball being tested, the forces also changed drastically (Table 1). With the old Molten ball, the forces changed considerably when the panel orientation changed. However, because the new volleyball (V200W) for the Tokyo Olympics is less dependent on panel orientation changes, similar results were obtained. Therefore, the flight trajectory of the new volleyball for the Tokyo Olympics is expected to be more stable than that of the old volleyball. 


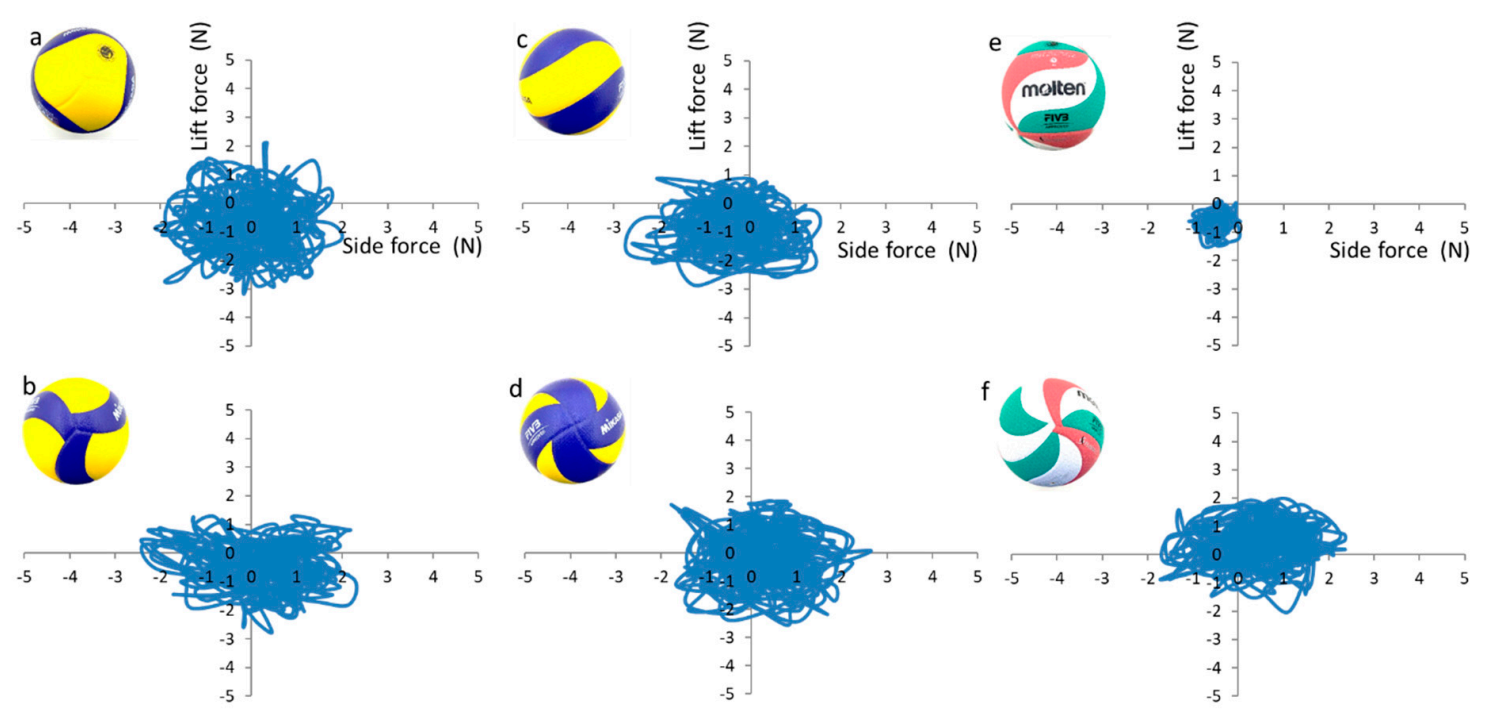

Figure 4. Scatter diagrams of changes in the lift and side forces acting on the balls in the wind tunnel test. In this figure, $(\mathbf{a}, \mathbf{b})$ represent the Face A and B orientation of the new Mikasa volleyball, respectively; (c,d) represent the Face A and B orientations of the old Mikasa volleyball, respectively; and $(\mathbf{e}, \mathbf{f})$ represent the Face A and B orientation of the old Molten volleyball, respectively (10 s, wind velocity of $15 \mathrm{~m} / \mathrm{s}$ ).

Table 1. Mean and standard deviation (SD) of the lift and side forces acting on the respective volleyballs (10 s, wind velocity of $15 \mathrm{~m} / \mathrm{s})$.

\begin{tabular}{|c|c|c|c|c|c|c|c|c|c|c|c|c|}
\hline \multirow[b]{2}{*}{ Type } & \multicolumn{2}{|c|}{ a } & \multicolumn{2}{|c|}{ b } & \multicolumn{2}{|c|}{ c } & \multicolumn{2}{|c|}{ d } & \multicolumn{2}{|c|}{ e } & \multicolumn{2}{|c|}{$\mathrm{f}$} \\
\hline & $\begin{array}{l}\text { Side } \\
\text { Force }\end{array}$ & $\begin{array}{c}\text { Lift } \\
\text { Force }\end{array}$ & $\begin{array}{l}\text { Side } \\
\text { Force }\end{array}$ & $\begin{array}{c}\text { Lift } \\
\text { Force }\end{array}$ & $\begin{array}{l}\text { Side } \\
\text { Force }\end{array}$ & $\begin{array}{c}\text { Lift } \\
\text { Force }\end{array}$ & $\begin{array}{l}\text { Side } \\
\text { Force }\end{array}$ & $\begin{array}{c}\text { Lift } \\
\text { Force }\end{array}$ & $\begin{array}{l}\text { Side } \\
\text { Force }\end{array}$ & $\begin{array}{c}\text { Lift } \\
\text { Force }\end{array}$ & $\begin{array}{l}\text { Side } \\
\text { Force }\end{array}$ & $\begin{array}{c}\text { Lift } \\
\text { Force }\end{array}$ \\
\hline Mean & -0.06 & -0.66 & 0.27 & -0.46 & -0.38 & -0.77 & 0.21 & -0.20 & -0.48 & -0.61 & 0.35 & 0.33 \\
\hline SD & 0.81 & 0.92 & 0.88 & 0.73 & 0.73 & 0.70 & 0.84 & 0.86 & 0.19 & 0.26 & 0.80 & 0.66 \\
\hline
\end{tabular}

\section{Conclusions}

This study examined the aerodynamic characteristics of the new volleyball (V200W) to be used in the 2020 Tokyo Olympics, and compared them with the characteristics of two types of balls currently in use (MVA200 and V5M5000) using a wind tunnel experiment.

The results revealed that the drag on the volleyballs varied according to their design. For the traditional balls (MVA200 and V5M5000), it was found that the Reynolds number increased and the drag coefficient varied substantially depending on the ball orientation. For the Molten ball, the shift in its $C d$ value to the supercritical region was revealed to be dramatically slower for Face B $\left(2.8 \times 10^{5}\right)$ than for Face A $\left(2.2 \times 10^{5}\right)$. On the basis of the results, drag on the conventional Molten ball substantially varies depending on its orientation, and thus, in comparison with the new ball, the Molten ball is thought to be more affected by panel orientation. The speed of a volleyball in a serve ranges between approximately 50 and $80 \mathrm{~km} / \mathrm{h}$, or $2.0 \times 10^{5}$ and $3.0 \times 10^{5}$ if converted to $R e$. In a volleyball spike (attack), the ball flies at up to $100 \mathrm{~km} / \mathrm{h}$ (approximately $4.2 \times 10^{5}$ ), but the changes in $C d$ owing to the volleyball type and its orientation were demonstrated to be relatively low at this speed. Moreover, with a velocity range of approximately $15 \mathrm{~m} / \mathrm{s}$ (Re of approximately $2.0 \times 10^{5}$ ), which is used in float serves, the $C d$ results change even more prominently with the ball type and panel orientation. Presumably, this is because the air resistance acting on the ball in float serves varies according to the volleyball type and panel orientation, and as a result, the flight trajectory is modified. For this reason, it is considered effective to consider the ball type and orientation when executing different types of serves in a volleyball, including float serves. 
Therefore, it can be determined that the flight distance of the Molten ball can be changed by changing its orientation. The newly designed volleyball for the 2020 Tokyo Olympics (V200W, 18-panels by Mikasa) is predicted to have a relatively stable flight distance, as the dependence of its drag variation on panel orientation is relatively small, and ball orientation has a lesser effect on its $C d$. Moreover, because the new volleyball is expected to have a more stable trajectory than that of the old ball, a longer rally can also be expected. These results suggest that the raised dimple-like pattern on the surface of the ball is effective at keeping the boundary line around the ball constant. The ball surface consists of complex factors such as the shape, number, width, and depth of the panels. Therefore, a more detailed examination of the air flow on the ball surface using visualization methods such as PIV (Particle Image Velocimetry) should be conducted. Furthermore, these results are likely to be used as scientific evidence to show that, in a volleyball, service aces can be affected by the variation of trajectory as a result of ball orientation, thus complementing prior studies that have reported on how the success of float serves greatly affects the positive outcome of a match [14-16].

In summary, knowledge about the flight characteristics of various official volleyballs can lead to better floating serves, which are thought to substantially contribute to service aces and the positive outcome of a match.

Author Contributions: Conceptualization: S.H., H.O., K.W. and T.A.; methodology: S.H., H.O., K.W. and T.A.; software: S.H.; data curation: S.H. and T.A.; writing—original draft preparation; S.H. and T.A.; writing—review and editing: S.H., H.O., K.W. and T.A. All authors have read and agreed to the published version of the manuscript.

Funding: This work was supported by JSPS KAKENHI (Grant No. 15K16442) of the Ministry of Education, Culture, Sports, Science and Technology of the Japanese government.

Conflicts of Interest: The authors declare no conflict of interest.

\section{References}

1. Asai, T.; Ito, S.; Seo, K.; Hitotsubashi, A. Fundamental aerodynamics of a new volleyball. Sports Technol. 2010, 3, 235-239. [CrossRef]

2. Hong, S.; Weon, B.M.; Nakanishi, Y.; Kimachi, K.; Seo, K.; Asai, T. Aerodynamic effects of a panel orientation in volleyball float serve. In Proceedings of the 2018 International Society of Biomechanics in Sports, Auckland, New Zealand, 10-14 September 2018; pp. 1-4.

3. Hong, S.; Asai, T.; Weon, B.M. Surface patterns for drag modification in volleyballs. Appl. Sci. 2019, 9, 4007. [CrossRef]

4. Naito, K.; Hong, S.; Koido, M.; Nakayama, M.; Sakamoto, K.; Asai, T. Effect of seam characteristics on critical Reynolds number in footballs. Mech. Eng. J. 2018, 5, 17-00369. [CrossRef]

5. Hong, S.; Asai, T. Effect of panel shape of soccer ball on its flight characteristics. Sci. Rep. 2014, 4, 5068. [CrossRef] [PubMed]

6. Hong, S.; Asai, T.; Seo, K. Visualization of air flow around soccer ball using a particle image velocimetry. Sci. Rep. 2015, 5, 15108. [CrossRef] [PubMed]

7. Goff, J.E.; Hong, S.; Asai, T. Effect of a soccer ball's seam geometry on its aerodynamics and trajectory. Proc. Inst. Mech. Eng. Part P J. Sports Eng. Technol. 2019, 234, 19-29. [CrossRef]

8. Goff, J.E.; Hong, S.; Asai, T. Aerodynamic and surface comparisons between Telstar 18 and Brazuca. Proc. Inst. Mech. Eng. Part P J. Sports Eng. Technol. 2018, 232, 342-348. [CrossRef]

9. Goff, J.E.; Asai, T.; Hong, S. A comparison of Jabulani and Brazuca non-spin aerodynamics. Proc. Inst. Mech. Eng. Part P J. Sports Eng. Technol. 2014, 228, 188-194. [CrossRef]

10. Passmore, M.A.; Rogers, D.; Tuplin, S.; Harland, A.; Lucas, T.; Holmes, C. The aerodynamic performance of a range of FIFA-approved footballs. Proc. Inst. Mech. Eng. Part P J. Sports Eng. Technol. 2011, 226, 61-70. [CrossRef]

11. Aoki, K.; Muto, K.; Okanaga, H. Aerodynamic characteristics and flow pattern of a golf ball with rotation. Procedia Eng. 2010, 2, 2431-2436. [CrossRef]

12. Djamovski, V.; Rosette, P.; Chowdhury, H.; Alam, F.; Steiner, T. A comparative study of rugby ball aerodynamics. Procedia Eng. 2012, 34, 74-79. [CrossRef] 
13. Price, D.S.; Jones, R.; Harland, A.R. Computational modelling of manually stitched soccer balls. Proc. Inst. Mech. Eng. Part L J. Mater. Des. Appl. 2006, 220, 259-268. [CrossRef]

14. Silva, M.; Lacerda, D.; João, P.V. Game-related volleyball skills that influence victory. J. Hum. Kinet. 2014, 41, 173-179. [CrossRef] [PubMed]

15. Zetou, E.; Moustakidis, A.; Tsigilis, N.; Komninakidou, A. Does effectiveness of skill in complex i predict win in men's Olympic volleyball games? J. Quant. Anal. Sports 2007, 3, 1559-1570. [CrossRef]

16. Marelic, N.; Resetar, T.; Jankovic, V. Discriminant analysis of the sets won and the sets lost by one team in a1 Italian volleyball league-A case study. Kinesiology 2004, 36, 75-82.

(C) 2020 by the authors. Licensee MDPI, Basel, Switzerland. This article is an open access article distributed under the terms and conditions of the Creative Commons Attribution (CC BY) license (http://creativecommons.org/licenses/by/4.0/). 